\title{
Incidence, Clinico-demographic Profiles and Survival Rates of Colorectal Cancer in Northern Malaysia: Comparing Patients Above and Below 50 Years of Age
}

\author{
Nik Razima Wan Ibrahim¹, Huan-Keat Chan ${ }^{2 *}$, Shahrul Aiman Soelar ${ }^{2}$, Ahmad \\ Najib Azmi ${ }^{3}$, Rosaida Mohd Said ${ }^{1}$, Muhammad Radzi Abu Hassan ${ }^{2,4}$
}

\begin{abstract}
Background: While the world witnesses an increasing trend of young-onset colorectal cancer (CRC), the information regarding the impact of age on CRC is limited in Malaysia. This study aimed to compare the incidence, clinic-demographic profiles and survival rates of CRC between patients above and under 50 years of age in northern Malaysia. Methods: This was a registry-based, cross-sectional study. All the CRC cases reported by 18 hospitals to the National Cancer Patient Registry - Colorectal Cancer (NCPR-CC) between January 2007 and December 2017 were included in the analysis. The patients were categorized by age into the above- 50 and under-50 groups. The changes in the age-standardized incidence and mortality rates of both the age groups were determined using the time-series analysis, and the impact of age on the mortality risk was assessed using the Cox regression analysis. Results: Of the 6,172 CRC patients enrolled in the NCPR-CC, 893 (14.5\%) were in the under-50 group. As compared with their older counterparts, the patients in the under-50 group were more likely to be female, be of Malay ethnicity, be non-smokers, have a family history of $\mathrm{CRC}$, and present late for treatment. The age-standardized incidence and mortality rates of $\mathrm{CRC}$ in the under-50 group remained stable over the years, while a decreasing trend was clearly seen in the mortality rates of CRC in the above-50 group ( $\mathrm{p}=0.003)$. Nevertheless, the two age groups also did not differ in the mortality risk (adjusted hazards ratio: 1.10; 95\% CI: 0.90, 1.36). Conclusion: Young-onset CRC constituted a considerable proportion of CRC cases in Malaysia. However, in contrast with the findings of most studies, it demonstrated neither an uptrend in age-standardized incidence rates nor a higher mortality risk. Our findings suggest the need to upscale and lower the recommended age for CRC screening in Malaysia.
\end{abstract}

Keywords: Colorectal neoplasms- early detection of cancer- Malaysia- survival rate

Asian Pac J Cancer Prev, 21 (4), 1057-1061

\section{Introduction}

Colorectal cancer (CRC) is the third most common cancer in men and the second in women worldwide. In 2018, the World Health Organization reported nearly 1.85 million new CRC cases and 0.88 million CRC-related deaths (Wong et al., 2019). Malaysia, together with China, Japan, Korea and Singapore, has recorded the highest 5-year prevalence of CRC $(\geq 46.5$ cases in 100,000$)$ in Asia (Haggar and Boushey, 2009).

It is well known that the prognosis of a CRC patient is strongly related to the stage at which the cancer is diagnosed. The 5-year survival rate of CRC is higher than $80 \%$ for stage 1 and 2 , between 30 and $60 \%$ for stage 3 , and lower than $10 \%$ for stage 4 (Rashid et al., 2009). Although the overall 5-year survival rate of CRC in Malaysia had considerably increased from $40 \%$ in the late 1990 's to $53 \%$ in the first 5 years after the millennium (Ghazali et al., 2010; Kong et al., 2010), most CRC patients are still diagnosed only at late stages (Veettil et al., 2017).

The incidence of CRC has also been shown to disproportionately increase with age, with $90 \%$ of the cases occurring in individuals aged 50 years and above (Feletto et al., 2019). Therefore, CRC screening, mainly by using colonoscopy or fecal occult blood testing (FOBT), is highly recommended for this age group globally. Large-scale screening programs and media campaigns have successfully driven the growth in the uptake of CRC screening, notably in western countries. In the US alone, the uptake of annual CRC screening in individuals aged

${ }^{1}$ Gastroenterology Unit, Department of Medicine, Ampang Hospital, Ampang, Selangor, ${ }^{2}$ Clinical Research Center, Sultanah Bahiyah Hospital, Alor Setar, ${ }^{3}$ Faculty of Medicine and Health Sciences, Islamic Science University of Malaysia, Kuala Lumpur, ${ }^{4}$ Gastroenterology Unit, Department of Medicine, Sultanah Bahiyah Hospital, Alor Setar, Malaysia. *For Correspondence: huankeat123@yahoo.com 
between 50 to 74 years had increased from $51.6 \%$ in 2008 to $61.3 \%$ in 2015 (de Moor et al., 2018). Early detection and removal of tumors or adenomatous polyps, along with the improved health consciousness and advances in cancer treatment, had resulted in a $30 \%$ decline in both the global incidence and mortality of CRC between 2003 and 2012 (Kopetz et al., 2009; Cone et al., 2011; Edwards et al., 2010; Siegel et al., 2012; Siegel et al., 2014; Siegel et al., 2017).

Ironically, since the early 1990 s, the US has also been witnessing an annual increase of nearly $2 \%$ in the incidence of CRC among individuals under 50 years of age (Myers et al., 2019). Delayed presentation for treatment is common in young CRC patients (Fu et al., 2014). Yet, regular CRC screening in young individuals remains controversial and is often deemed to be less cost-effective. Despite the same concern raised about the early-onset CRC in Malaysia (Veettil et al., 2017), the information regarding this issue is still limited. As an initial step to fill this gap, this study was designed to compare the incidence, clinic-demographic profiles and survival rates of CRC between patients above and under 50 years of age in northern Malaysia.

\section{Materials and Methods}

This registry-based, cross-sectional study focused on three states in northern Malaysia (Perlis, Kedah and Penang), as all the 18 public and private hospitals in this region have been reporting all the CRC cases encountered by them to the National Cancer Patient Registry - Colorectal Cancer (NCPR-CC) since its inception back in 2007. All the CRC patients enrolled in the NCPR-CC between January 2007 and December 2017 were included in this the analysis. The patient information gathered from the NCPR-CC included age, gender, ethnicity, smoking status, diabetes mellitus (DM) status, family history of CRC, symptoms at presentation, treatment, cancer stage at diagnosis, and survival status up until December 2017.

The patients were subsequently dichotomized by age into the above-50 ( $\geq 50$ years of age) and under-50 $(<50$ years of age) groups. For each age group, based on the population data provided by the Department of Statistics (2010), the crude and age-standardized incidence and mortality rates of CRC from 2007 to 2017 were calculated and presented as the number of cases in 100,000 (Ahmad et al., 2010). Their changes over the years were subsequently assessed using the time series analysis. Furthermore, the demographic and clinical profiles of the two age groups were summarized as frequencies and percentages, and were compared using the Pearson's chi-square tests of independence. Apart from that, the 3- and 5-year survival rates of both the age groups were expressed as percentages and $95 \%$ confidence intervals (CIs). The impact of age on the mortality risk was also assessed using the Cox regression analysis, with the results summarized as hazards ratios (HRs) and 95\% CIs. The data analysis was performed using the R-3.5.1 for Windows. All the statistical tests were two-sided, with the significant level fixed at $5 \%$.

\section{Results}

Over the 11-year period studied, a total of 6,172 CRC cases were reported to the NCPR-CC. Eight hundred ninety-three (14.5\%) of the patients were under 50 years of age, and nearly $70 \%$ of them were in the age range of 40 to 49 years. The overall age-standardized incidence rates of CRC were 169.86 and 25.23 cases in 100,000 for the above- 50 and under- 50 groups, respectively. The above- 50 group also recorded a higher overall age-standardized mortality rate as compared with the under-50 group (95.57 vs. 12.17 cases in 100,000$)$. However, only the above-50 group demonstrated a decreasing trend in the mortality rates over years $(\mathrm{p}=0.003)$ (Table 1$)$.

Table 1. Incidence and Mortality Rates (Number of Cases in 100,000) by Age of Colorectal Cancer Patients, 2007-2017

\begin{tabular}{|c|c|c|c|c|c|c|c|c|c|c|c|c|c|c|c|}
\hline \multirow[t]{2}{*}{ Variables } & \multirow{2}{*}{$\begin{array}{l}\text { Overall, } \\
\mathrm{n}=6,172\end{array}$} & \multicolumn{11}{|c|}{ Year } & \multicolumn{3}{|c|}{ Time-series analysis } \\
\hline & & $\begin{array}{c}2007 \\
n=426\end{array}$ & $\begin{array}{c}2008 \\
\mathrm{n}=575\end{array}$ & $\begin{array}{c}2009 \\
\mathrm{n}=590\end{array}$ & $\begin{array}{c}2010 \\
\mathrm{n}=601\end{array}$ & $\begin{array}{c}2011 \\
\mathrm{n}=537\end{array}$ & $\begin{array}{c}2012 \\
\mathrm{n}=536\end{array}$ & $\begin{array}{c}2013 \\
\mathrm{n}=548\end{array}$ & $\begin{array}{c}2014 \\
n=553\end{array}$ & $\begin{array}{c}2015 \\
\mathrm{n}=618\end{array}$ & $\begin{array}{c}2016 \\
n=634\end{array}$ & $\begin{array}{c}2017 \\
n=554\end{array}$ & $\beta$ & $P$-value & Trend \\
\hline \multicolumn{16}{|c|}{ Incidence (in 100,000 ) } \\
\hline \multicolumn{16}{|c|}{ Under-50 group } \\
\hline $\mathrm{CR}$ & 24.96 & 1.84 & 2.54 & 2.26 & 2.71 & 1.84 & 2.07 & 2.29 & 2.54 & 2.38 & 2.21 & 2.26 & 0.011 & 0.700 & Stable \\
\hline ASR & 25.23 & 1.85 & 2.57 & 2.26 & 2.72 & 1.87 & 2.12 & 2.30 & 2.58 & 2.41 & 2.26 & 2.29 & 0.014 & 0.618 & Stable \\
\hline \multicolumn{16}{|c|}{ Above-50 group } \\
\hline $\mathrm{CR}$ & 147.54 & 10.06 & 13.53 & 14.23 & 14.09 & 13.16 & 12.91 & 13.02 & 12.91 & 14.90 & 15.51 & 13.22 & 0.211 & 0.118 & Stable \\
\hline ASR & 169.86 & 11.61 & 15.64 & 16.55 & 16.19 & 15.18 & 14.92 & 15.02 & 14.86 & 16.86 & 17.76 & 15.28 & 0.227 & 0.137 & Stable \\
\hline \multicolumn{16}{|c|}{ Mortality (in 100,000 ) } \\
\hline \multicolumn{16}{|c|}{ Under-50 group } \\
\hline $\mathrm{CR}$ & 12.02 & 0.87 & 1.31 & 1.20 & 1.54 & 1.03 & 1.17 & 1.23 & 1.51 & 1.09 & 0.75 & 0.31 & -0.048 & 0.168 & Stable \\
\hline ASR & 12.17 & 0.87 & 1.34 & 1.20 & 1.53 & 1.05 & 1.20 & 1.24 & 1.54 & 1.11 & 0.78 & 0.30 & -0.048 & 0.168 & Stable \\
\hline \multicolumn{16}{|c|}{ Above- 50 group } \\
\hline $\mathrm{CR}$ & 81.64 & 7.32 & 9.70 & 10.28 & 9.31 & 8.44 & 8.13 & 7.24 & 6.74 & 6.99 & 5.23 & 2.26 & -0.047 & 0.182 & Stable \\
\hline ASR & 95.57 & 8.57 & 11.39 & 12.14 & 10.85 & 9.92 & 9.55 & 8.46 & 7.81 & 8.07 & 6.13 & 2.68 & -0.540 & 0.003 & Decreasing \\
\hline
\end{tabular}

CR, crude rate; ASR, age-standardized rate. 
Table 2. Demographic and Clinical Characteristics of the under-50 and above-50 Groups, 2007-2017

\begin{tabular}{|c|c|c|c|c|c|c|c|}
\hline \multirow[t]{3}{*}{ Variables } & \multirow{2}{*}{\multicolumn{2}{|c|}{$\begin{array}{c}\text { All patients, } \\
\mathrm{n}=6,172^{\mathrm{a}}\end{array}$}} & \multicolumn{4}{|c|}{ Age groups } & \multirow[t]{3}{*}{$P$-value ${ }^{b}$} \\
\hline & & & \multicolumn{2}{|c|}{$\begin{array}{c}<50 \text { years } \\
\mathrm{n}=893\end{array}$} & \multicolumn{2}{|c|}{$\begin{array}{c}\geq 50 \text { years } \\
n=5,279\end{array}$} & \\
\hline & $\mathrm{N}$ & $(\%)$ & $\mathrm{n}$ & $(\%)$ & $\mathrm{n}$ & $(\%)$ & \\
\hline Gender & & & & & & & 0.015 \\
\hline Male & 3,342 & $(54.1)$ & 450 & $(50.4)$ & 2,892 & $(54.8)$ & \\
\hline Female & 2,830 & $(45.9)$ & 443 & $(49.6)$ & 2,387 & $(45.2)$ & \\
\hline Ethnicity & & & & & & & $<0.001$ \\
\hline Malay & 2,216 & $(35.9)$ & 453 & $(50.7)$ & 1,763 & (33.4) & \\
\hline Chinese & 3,503 & $(56.8)$ & 348 & $(39.0)$ & 3,155 & $(59.8)$ & \\
\hline Indian & 382 & $(6.2)$ & 74 & $(8.3)$ & 308 & $(5.8)$ & \\
\hline Others & 71 & $(1.2)$ & 18 & $(2.0)$ & 53 & $(1.0)$ & \\
\hline Smoking status & & & & & & & $<0.001$ \\
\hline Never & 1,811 & $(29.3)$ & 295 & $(33.0)$ & 1,516 & $(28.7)$ & \\
\hline Quitting $\geq 30$ days & 330 & $(5.3)$ & 67 & $(7.5)$ & 263 & $(5.0)$ & \\
\hline Active & 500 & $(8.1)$ & 47 & $(5.3)$ & 453 & $(8.6)$ & \\
\hline Family history of colorectal cancer & & & & & & & $<0.001$ \\
\hline No & 3,075 & $(49.8)$ & 431 & $(48.3)$ & 2,644 & $(50.1)$ & \\
\hline Yes & 186 & $(3.0)$ & 48 & $(5.4)$ & 138 & $(2.6)$ & \\
\hline \multicolumn{8}{|l|}{ Symptoms at presentation } \\
\hline Alteration of bowel habit & 1,937 & $(31.4)$ & 278 & $(31.1)$ & 1,659 & $(31.4)$ & 0.860 \\
\hline Abdominal or anal pain & 1,583 & $(25.6)$ & 266 & $(29.8)$ & 1,317 & $(24.9)$ & 0.002 \\
\hline Blood in the stool or rectal bleeding & 1,564 & $(25.3)$ & 216 & $(24.2)$ & 1,348 & $(25.5)$ & 0.392 \\
\hline Weight loss & 1,124 & $(18.2)$ & 163 & $(18.3)$ & 961 & $(18.2)$ & 0.972 \\
\hline Anemia & 430 & $(7.0)$ & 57 & $(6.4)$ & 373 & $(7.1)$ & 0.459 \\
\hline Appetite loss & 427 & $(6.9)$ & 53 & $(5.9)$ & 374 & $(7.1)$ & 0.211 \\
\hline Intestinal obstruction & 356 & $(5.8)$ & 66 & $(7.4)$ & 290 & $(5.5)$ & 0.025 \\
\hline \multicolumn{8}{|l|}{ Treatment received } \\
\hline Surgery & 4,523 & $(73.3)$ & 676 & (75.7) & 3,847 & (72.9) & 0.078 \\
\hline Chemotherapy and biological Therapy & 2,120 & $(34.3)$ & 442 & $(49.5)$ & 1,678 & $(31.8)$ & $<0.001$ \\
\hline Radiotherapy & 854 & $(13.8)$ & 154 & $(17.2)$ & 700 & $(13.3)$ & 0.001 \\
\hline Supportive or palliative care & 270 & $(4.4)$ & 30 & $(3.4)$ & 240 & $(4.5)$ & 0.109 \\
\hline Diabetes mellitus status & & & & & & & $<0.001$ \\
\hline No & 2,883 & $(46.7)$ & 503 & $(56.3)$ & 2,380 & $(45.1)$ & \\
\hline Yes & 1,042 & $(16.9)$ & 65 & $(7.3)$ & 977 & $(18.5)$ & \\
\hline Primary cancer site & & & & & & & 0.274 \\
\hline Left side & 4,047 & $(65.6)$ & 562 & $(62.9)$ & 3,485 & $(66.0)$ & \\
\hline Right side & 554 & $(9.0)$ & 72 & $(8.1)$ & 482 & $(9.1)$ & \\
\hline Both sides & 104 & (1.7) & 9 & $(1.0)$ & 95 & $(1.8)$ & \\
\hline Cancer stage at diagnosis & & & & & & & 0.002 \\
\hline I & 416 & (6.7) & 52 & $(5.8)$ & 364 & (6.9) & \\
\hline II & 1,081 & $(17.5)$ & 135 & $(15.1)$ & 946 & (17.9) & \\
\hline III & 1,311 & $(21.2)$ & 206 & (23.1) & 1,105 & (20.9) & \\
\hline IV & 1,121 & (18.2) & 201 & (22.5) & 920 & (17.4) & \\
\hline
\end{tabular}

a, Incomplete information is reported for smoking status $(n=3,531 ; 57.2 \%)$; family history of colorectal cancer ( $n=2,911 ; 47.2 \%)$, diabetes mellitus status $(\mathrm{n}=2,247 ; 36.4 \%)$, primary cancer site $(\mathrm{n}=1,467 ; 23.8 \%)$ and cancer stage at diagnosis $(2,243,36.3 \%)$; ${ }^{\text {b }}$, Pearson's chi-square test of independence.

Most of the CRC patients were male (54.1\%), of Chinese ethnicity (56.8\%) and non-smokers (29.3\%). Only $3.0 \%$ of them had a family history of CRC. However, as compared with the above-50 group, the under-50 group was more likely to be female ( $49.6 \%$ vs. $45.2 \%$; $\mathrm{p}=0.015$ ), be of Malay ethnicity (50.7\% vs. $33.4 \%$; p $<0.001)$, be non-smokers $(33.0 \%$ vs. $28.7 \%$; $<<0.001)$, and have a family history of CRC (5.4\% vs. $2.6 \%$; $<<0.001)$. The most 
Table 3. Survival Rates of the under-50 and above-50 Groups and Results of Survival Analysis, 2007-2017

\begin{tabular}{|c|c|c|c|c|c|c|}
\hline \multirow[t]{2}{*}{ Variables } & \multicolumn{2}{|c|}{ Survival Rate, $\%$} & \multicolumn{2}{|c|}{ Simple Cox Regression } & \multicolumn{2}{|c|}{ Multiple Cox Regression ${ }^{a}$} \\
\hline & 3 years $(95 \% \mathrm{CI})$ & 5 years $(95 \% \mathrm{CI})$ & Crude HR $(95 \% \mathrm{CI})$ & p-value & Adjusted HR (95\% CI) & $\mathrm{p}$-value \\
\hline \multicolumn{7}{|l|}{ Age groups } \\
\hline$<50$ years & $60.04(54.0,66.8)$ & $48.41(42.0,55.9)$ & 1.00 (ref.) & & 1.00 (ref.) & \\
\hline$\geq 50$ years & $59.52(56.9,62.3)$ & $50.67(47.8,53.7)$ & $1.03(0.84,1.25)$ & 0.801 & $1.10(0.90,1.36)$ & 0.359 \\
\hline
\end{tabular}

CI, confidence interval; HR; hazards ratio; a, Adjusted for gender, ethnicity, smoking status, family history of colorectal cancer, symptoms at presentation, treatment received, diabetes mellitus status, primary cancer site and cancer stage at diagnosis. A total of 1,563 patients with complete documentation for all the variables listed were included in the model.

common symptoms at presentation included the alteration of bowel habit (31.4\%), abdominal or anal pain (25.6\%), and the presence of blood in the stool or rectal bleeding (25.3\%). Abdominal or anal pain (29.8\% vs. 24.9\%; $\mathrm{p}=0.002)$ and intestinal obstruction $(7.4 \%$ vs. $5.5 \%$; $\mathrm{p}=0.025)$ were more commonly seen in the under-50 group. DM, on the other hand, was more prevalent in the above-50 group ( $18.5 \%$ vs. $7.3 \%$; $p<0.001)$ (Table 2 ).

In both the age groups, more than $60 \%$ of the patients first presented with left-sided CRC. Nevertheless, the under-50 group was more likely to be diagnosed at advanced stages (III or IV) $(45.6 \%$ vs. $38.3 \%$; $p=0.002)$ of CRC, as well as to receive chemotherapy and biological therapy $(49.5 \%$ vs. $31.8 \% ; \mathrm{p}<0.001)$ and radiotherapy (17.2\% vs. $13.3 \%$; $=0.001$ ) (Table 2 ). Yet, the two age groups did not considerably differ in both the 3- and 5-year survival rates. Additionally, it is found that the age of patients, dichotomized by using 50 years as the cut-off, was not a significant predictor of mortality (adjusted hazards ratio: $1.10 ; 95 \% \mathrm{CI}: 0.90,1.36 ; \mathrm{p}=0.359$ ) (Table 3).

\section{Discussion}

Although the incidence of CRC remarkably increases after the fifth decade of life, the proportion of patients under 50 years of age has increased to more than $10 \%$ worldwide (Fu et al., 2014). In agreement with the previous findings, our study shows that $14.5 \%$ of the CRC patients in northern Malaysia were in the young age group.

Yet, it is noteworthy that the actual number of patients aged below 50 years could be underestimated in our study. Instead of an uptrend in the incidence of early-onset CRC as shown in most countries (Myers et al., 2019), our study reports a stable trend between 2007 and 2017. This could be attributed to the under-diagnosis of CRC in the young population. In Malaysia, CRC screening has only been highly recommended for older patients, and young individuals are generally regarded as the low-risk group. This could also explain why most young CRC patients only sought treatment at advanced stages of the disease in Malaysia.

While it is widely believed that early-onset CRC is strongly related to genetic factors, our study did find that the under-50 group was more likely to have a family history of CRC. Nonetheless, the proportion of young patients with a family history of CRC shown in our study (5.4\%) was much lower than that reported by a recent review (20\%) (Mauri et al., 2019). Additionally, it is noted that the young patients had a higher tendency to present late for treatment. Overall, our findings implies under-screening for $\mathrm{CRC}$ in the at-risk young population in the country.

Interestingly, early-onset CRC, consistent with the findings of a local study back in 1998, was found to be more prevalent in the Malay ethnic group, even though the Chinese ethnic group constitutes the largest proportion of CRC cases in Malaysia (Veettil et al., 2017). The ethnic variations in the incidence of early-onset CRC are likely due to the differences in health consciousness and the awareness of the disease. However, more studies are required to verify and explain such findings.

Unlike most studies (Siegel et al., 2019), our study only showed a declining trend in the mortality but not in the incidence rates of CRC in the above-50 group. Moreover, in contrast to the previous findings $(\mathrm{Fu}$ et al., 2014), the older patients were not shown to have a lower mortality risk as compared with their younger counterparts. It is clear that the public awareness of CRC is still limited regardless of age in Malaysia, and the uptake of CRC screening in the targeted age group is also yet to be optimized (Hilmi et al., 2010; Al-Naggar and Bobryshev, 2013).

While the Clinical Practice Guidelines of Colorectal Carcinoma recently launched by the Malaysia Health Technology Assessment Section (2017) recommends CRC screening in individuals above 50 years of age, it is noteworthy that approximately $70 \%$ of the young patients in our study were in the age range of 40 to 49 years. A similar observation was reported by the US and Taiwan (Chen et al., 2016; Mannucci et al., 2019). All these findings are suggestive of the need for adopting the proposal of the American Cancer Society to further lower the recommended age for CRC screening in Malaysia (Wolf et al., 2018). This can potentially help detect cancer at earlier stages in more patients and, in turn, save more lives.

As our study is only limited to only three states, a nationwide study is required to comprehensively explore the epidemiology and risk factors of early-onset CRC in the country. Additionally, the analysis was limited to the information reported to the NPPR-CC. Due to the incomplete documentation, only 1,563 patients were included in the Cox regression analysis. While the extension of CRC screening to younger patients is suggested based on our findings, further studies on its cost-effectiveness are also warranted.

In conclusion, as in many countries, the under-50 group was found to compose a considerable proportion of CRC patients in northern Malaysia. Nevertheless, 
the age-standardized incidence and mortality rates of CRC in this group was not shown to increase with time. Although the above-50 group showed a decreasing trend in the age-standardized mortality rates over the years as expected, it did not have a lower mortality risk as compared with the under-50 group. Our findings are suggestive of the need to scale up and, if feasible, to lower the recommended age for CRC screening in Malaysia.

\section{Acknowledgements}

We would like to thank the Director General of Health, Malaysia, for his permission to publish the findings from this study. We also acknowledged the contribution of all the 18 hospitals in Northen Malaysia to the NCPR-CC over the years.

\section{References}

Ahmad OB, Boschi-Pinto C, Lopez AD, et al (2001). Age Standardization of Rates: A New WHO Standard. World Health Organization, pp 3-7.

Al-Naggar RA, Bobryshev YV (2013). Knowledge of colorectal cancer screening among young Malaysians. Asian Pac J Cancer Prev, 14, 1969-74.

Chen CH, Tsai MK, Wen CP (2016). Extending colorectal cancer screening to persons aged 40 to 49 years with immunochemical fecal occult blood test: A prospective cohort Study of 513,283 Individuals. J Clin Gastroenterol, 50, 761-8.

Cone MM, Herzig DO, Diggs BS, et al (2011). Dramatic decreases in mortality from laparoscopic colon resections based on data from the Nationwide Inpatient Sample. Arch Surg, 146, 594-9.

de Moor JS, Cohen RA, Shapiro JA, et al (2018). Colorectal cancer screening in the United States: Trends from 2008 to 2015 and variation by health insurance coverage. Prev Med, 112, 199-206.

Department of Statistics Malaysia (2010). Population distribution by state. In 'Population Distribution and Basic Demographic Characteristics'. Ministry of Health, Malaysia, pp 2-6.

Edwards BK, Ward E, Kohler BA, et al (2010). Annual report to the nation on the status of cancer, 1975-2006, featuring colorectal cancer trends and impact of interventions (risk factors, screening, and treatment) to reduce future rates. Cancer, 116, 544-73.

Feletto E, Yu XQ, Lew JB, et al (2019). Trends in colon and rectal cancer incidence in Australia from 1982 to 2014: Analysis of data on over 375,000 cases. Cancer Epidemiol Biomarkers Prev, 28, 83-90.

Fu J, Yang J, Tan Y, et al (2014). Young patients ( $\leq 35$ years old) with colorectal cancer have worse outcomes due to more advanced disease: a 30-year retrospective review. Medicine (Baltimore), 93, e135.

Ghazali AK, Musa KI, Naing NN, Mahmood Z (2010). Prognostic factors in patients with colorectal cancer at Hospital Universiti Sains Malaysia. Asian J Surg, 33, 127-33.

Malaysia Health Technology Assessment Section (2017). Clinical Practice Guidelines--Management of Colorectal Carcinoma. Ministry of Health, Malaysia, pp 1-10.

Mauri G, Sartore-Bianchi A, Russo AG, et al (2019). Early-onset colorectal cancer in young individuals. Mol Oncol, 13, 109-31.

Haggar FA, Boushey RP (2009). Colorectal cancer epidemiology: incidence, mortality, survival, and risk factors. Clin Colon
Rectal Surg, 22, 191-7.

Hilmi I, Hartono JL, Goh K (2010). Negative perception in those at highest risk--potential challenges in colorectal cancer screening in an urban Asian population. Asian Pac J Cancer Prev, 11, 815-22.

Kong CK, Roslani AC, Law CW, Law SC, Arumugam K (2010). Impact of socio-economic class on colorectal cancer patient outcomes in Kuala Lumpur and Kuching, Malaysia. Asian Pac J Cancer Prev, 11, 969-74.

Kopetz S, Chang GJ, Overman MJ, et al (2009). Improved survival in metastatic colorectal cancer is associated with adoption of hepatic resection and improved chemotherapy. J Clin Oncol, 27, 3677-83.

Mannucci A, Zuppardo RA, Rosati R et al (2019). Colorectal cancer screening from 45 years of age: Thesis, antithesis and synthesis. World J Gastroenterol, 25, 2565-80.

Myers EA, Feingold DL, Forde KA, et al (2013). Colorectal cancer in patients under 50 years of age: a retrospective analysis of two institutions' experience. World J Gastroenterol, 19, 5651-7.

Rashid MR, Aziz AF, Ahmad S, Shah SA, Sagap I (2009). Colorectal cancer patients in a tertiary referral centre in Malaysia: a five year follow-up review. Asian Pac J Cancer Prev, 10, 1163-6.

Siegel R, DeSantis C, Jemal A (2014). Colorectal cancer statistics, 2014. CA Cancer J Clin, 64, 104-17.

Siegel RL, Miller KD, Fedewa SA (2017). Colorectal cancer statistics, 2017. CA Cancer J Clin, 67, 177-93.

Siegel RL, Ward EM, Jemal A (2012). Trends in colorectal cancer incidence rates in the United States by tumor location and stage, 1992-2008. Cancer Epidemiol Biomarkers Prev, 21, 411-6.

Siegel RL, Torre LA, Soerjomataram I, et al (2019). Global patterns and trends in colorectal cancer incidence in young adults. Gut, 68, 2179-85.

Veettil SK, Lim KG, Chaiyakunapruk N, Ching SM, Abu Hassan MR (2017). Colorectal cancer in Malaysia: its burden and implications for a multiethnic country. Asian J Surg, 40, 481-9.

Wolf AMD, Fontham ETH, Church TR, et al (2018). Colorectal cancer screening for average-risk adults: 2018 guideline update from the American Cancer Society. CA Cancer J Clin, 68, 250-81.

Wong MC, Ding H, Wang J, et al (2019). Prevalence and risk factors of colorectal cancer in Asia. Intest Res, 17, 317-29.

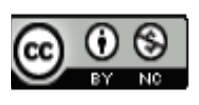

This work is licensed under a Creative Commons AttributionNon Commercial 4.0 International License. 